\title{
Regulation of energy homeostasis by GPR41
}

\author{
Daisuke Inoue ${ }^{1 * \dagger}$, Gozoh Tsujimoto ${ }^{1}$ and Ikuo Kimura ${ }^{1,2}{ }^{* \dagger}$ \\ ${ }^{1}$ Department of Pharmacogenomics, Kyoto University Graduate School of Pharmaceutical Sciences, Kyoto, Japan \\ ${ }^{2}$ Department of Applied Biological Science, Graduate School of Agriculture, Tokyo University of Agriculture and Technology, Fuchu-shi, Japan
}

\section{Edited by:}

Atsuhiko Ichimura, Tohoku University

Graduate School of Medicine, Japan

\section{Reviewed by:}

Julianne Toohey, University of

California Irvine Medical Center, USA

Magdalena Alicja Maj, Baylor College

of Medicine, USA

*Correspondence:

Daisuke Inoue, Department of Pharmacogenomics, Kyoto University

Graduate School of Pharmaceutical

Sciences, 46-29, Simoadachi-cho

Sakyo-ku, Kyoto 606-8501, Japan

e-mail: inodai820@gmail.com;

Ikuo Kimura, Department of Applied

Biological Science, Graduate School

of Agriculture, Tokyo University of

Agriculture and Technology, 3-8-1,

Harumi-cho, Fuchu-shi, Tokyo

183-0057, Japan

e-mail: ikimura@cc.tuat.ac.jp

${ }^{+}$Daisuke Inoue and Ikuo Kimura have

contributed equally to this work.
Imbalances in energy regulation lead to metabolic disorders such as obesity and diabetes. Diet plays an essential role in the maintenance of body energy homeostasis by acting not only as energy source but also as a signaling modality. Excess energy increases energy expenditure, leading to a consumption of it. In addition to glucose, mammals utilize shortchain fatty acids (SCFAs), which are produced by colonic bacterial fermentation of dietary fiber, as a metabolic fuel. The roles of SCFAs in energy regulation have remained unclear, although the roles of glucose are well-studied. Recently, a G-protein-coupled receptor deorphanizing strategy successfully identified GPR41 (also called free fatty acid receptor 3 or FFAR3) as a receptor for SCFAs. GPR41 is expressed in adipose tissue, gut, and the peripheral nervous system, and it is involved in SCFA-dependent energy regulation. In this mini-review, we focus on the role of GPR41 in host energy regulation.

Keywords: GPR41, FFAR3, energy regulation, short-chain fatty acid, gut microbiota

\section{INTRODUCTION}

Dysfunctional energy regulation leads to a variety of metabolic disorders, including obesity $(1,2)$. Mammals utilize not only glucose as the main energy source, but also short-chain fatty acids (SCFAs), such as acetate, propionate, and butyrate, which are produced by colonic bacterial fermentation of dietary fiber, in a significant proportion of their daily energy requirement $(3,4)$. The connections between gut microbiota, energy homeostasis, and the pathogenesis of metabolic disorders are now well-established $(5,6)$. In 2003, several groups reported that two orphan G-protein-coupled receptors (GPCR), namely GPR41 (also called free fatty acid receptor 3 or FFAR3) and GPR43 (also called free fatty acid receptor 2 or FFAR2), are activated by SCFAs $(7,8)$. GPR41 is reported to couple with $\mathrm{Gi} / \mathrm{o}$ protein. It is also reported that GPR41 is expressed in adipose tissue, the gut, and the peripheral nervous system. Moreover, GPR41 is reported to be involved in energy regulation in response to SCFAs produced from the gut microbiota. In the following sections, we discuss the role of GPR41 in host energy regulation.

\section{ADIPOSE TISSUE}

In adipose tissue, the role of GPR41 in the release of leptin, a polypeptide hormone with pleiotropic effects on appetite and energy metabolism, is the subject of much discussion. Gpr41 mRNA is known to be expressed in human (7-9) and mouse (10) adipose tissue. Xiong et al. showed that propionate-stimulated activation of GPR41 increases the release of leptin (10). In mice, oral administration of propionate increased plasma leptin levels (10). Furthermore, in experiments using Ob-Luc cells, leptin secretion was increased through overexpression of exogenous Gpr41 and was decreased by siRNA-mediated knockdown of Gpr41 (10). Another group showed that propionate-dependent increase in Leptin mRNA and protein levels could be inhibited by pretreatment with the Gi/o protein inhibitor, pertussis toxin (9).

However, Hong et al. (11) were unable to detect Gpr41 mRNA in differentiated 3T3-L1 cells or in mouse white adipose tissue (subcutaneous, perirenal, mesenteric, and epididymal fat pads) (11), even though they used the same PCR primers as Xiong et al. (10). We also previously reported that Gpr41 expression could not be detected in mouse adipose tissue by quantitative RTPCR or in situ hybridization analysis $(12,13)$. In contrast, Gpr43 mRNA, rather than Gpr41 mRNA, is expressed in mouse adipose tissues $(11,13,14)$. Zaibi et al. showed that acetate, rather than butyrate, stimulates leptin secretion by mesenteric adipocytes in wild-type mice (14). GPR41 is activated equally by propionate and butyrate, whereas GPR 43 is preferentially activated by propionate rather than butyrate (7). Because of the difference in ligand preference between GPR41 and GPR43, it was suggested that SCFA-stimulated leptin secretion is mediated by GPR43, rather than GPR41 (14). To clarify these discrepancies, the generation of adipose tissue-specific Gpr41 or Gpr43 knockout mice will be invaluable.

\section{GUT}

In the gut, GPR41 regulates host energy balance by modulating gut motility. By using in situ hybridization analysis, Samuel et al. showed that mouse Gpr41 mRNA is expressed in cells with the 
morphologic appearance of enteroendocrine cells (15). The body weight and fat pad weight of Gpr41 knockout mice are significantly reduced compared to wild-type mice, and this difference is abolished in germ-free conditions (15). These results indicate that the function of GPR41 depends on the SCFA produced by the fermentation of microbiota. Tazoe and colleagues also found the human Gpr41 is expressed in peptide YY (PYY)-containing enteroendocrine cells (16). Recently, several groups have confirmed Gpr41 mRNA expression in mouse intestinal L cells, which secrete incretin hormones such as GLP-1 and PYY $(17,18)$. Samuel and colleagues (15) showed that co-colonization of human gutderived microbiota in germ-free mice led to significantly increased circulating levels of PYY, which suppresses gut motility. Furthermore, this increase was significantly suppressed in their Gpr41 knockout littermates, although Gpr41 deletion did not affect the amount of chow consumption. Intestinal transit rate was significantly faster in Gpr41 knockout mice compared with wild-type littermates; this phenotype was abolished in germ-free conditions. Moreover, the SCFA content in feces of Gpr41 knockout mice was significantly higher than in wild-type mice. These results led the authors suggest that the decreased PYY level in Gpr41 knockout mice increases gut motility, which leads to reduced SCFA absorption and consequently a lean phenotype (15).

In contrast, Bellahcene et al. reported a male-specific increase in body fat mass of Gpr41 knockout mice when compared to their wild-type littermates; this was observed when mice were fed with either a low- or high-fat diet (19). Deletion of Gpr41 had no effect on the amount of food intake by either sex, regardless of the type of diet. This included mice of the same age (10 weeks) as those used in the report by Samuel and colleagues (15). The differences in sex hormones could explain why the energy expenditure of female Gpr41 knockout mice is similar to that of wild-type mice. Nevertheless, it is also possible that reduced SCFA absorption due to increased gut motility is responsible for the alleviation of obesity in Gpr41 knockout mice (19). Alternatively, reduced energy expenditure in Gpr41 knockout mice might be caused by reduced sympathetic activity (see Peripheral Nervous System below).

The altered body weight of Gpr41 knockout mice may be due to differences in genetic backgrounds, or due to the precise constitution of gut microbiota in each animal cohort.

Tolhurst et al. suggested that SCFAs could directly enhance the release of incretin hormones such as GLP-1 and PYY from L cells in gut. In Gpr41 knockout mice, glucose-stimulated GLP-1 secretion was lower than wild-type mice (17); this was confirmed by Nøhr et al. using the GPR41-selective agonist, AR420626 (18). Consistent with these findings, oral glucose tolerance was impaired in Gpr41 knockout mice (17).

\section{PERIPHERAL NERVOUS SYSTEM}

GPR41 regulates host energy balance by modulating sympathetic activity and intestinal gluconeogenesis. By using in situ hybridization and quantitative RT-PCR analysis, we have reported that Gpr41 mRNA is abundantly expressed in the mouse sympathetic ganglion (12). Gpr41 knockout mice exhibit a retardation of sympathetic nerve growth. However, further studies will be required to elucidate the precise molecular mechanism by which GPR41 modulates sympathetic nerve differentiation and growth.

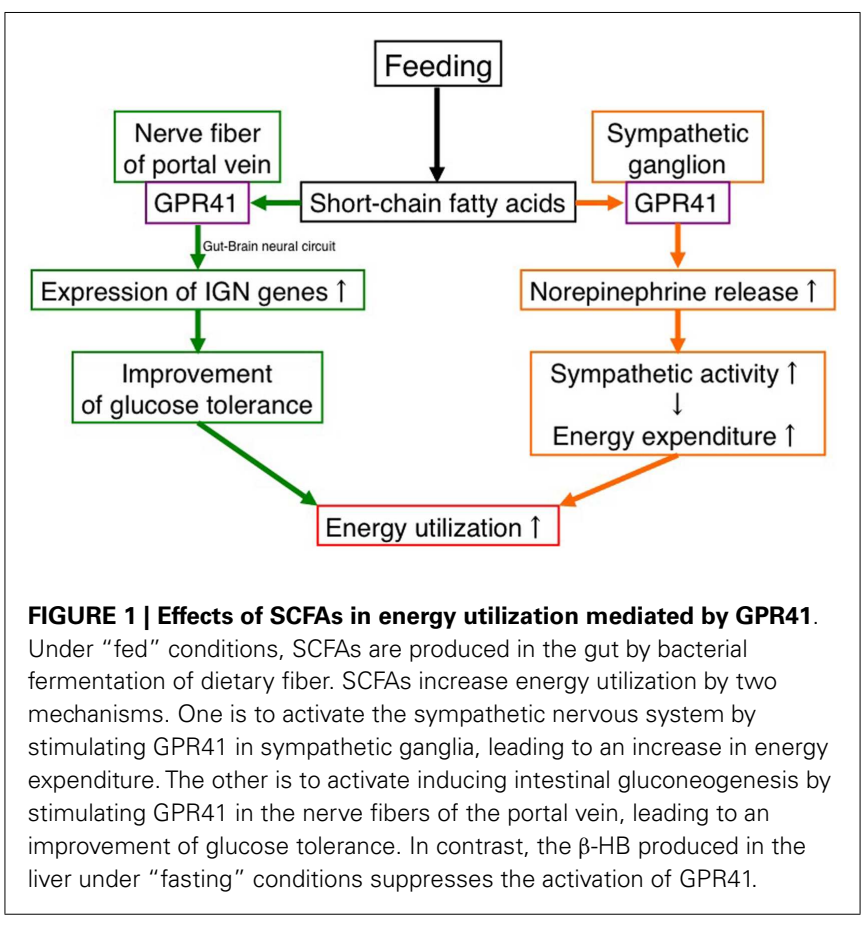

In adult wild-type mice, energy expenditure and heart rate are increased by propionate administration; these effects are abolished in Gpr41 knockout mice (12). The effect of propionate on the heart rate is inhibited by pretreatment with the $\beta$-adrenergic receptor blocker propranolol, but not by the nicotinic acetylcholine receptor blocker hexamethonium. These results indicate that propionate activates the sympathetic nervous system (SNS) via GPR41 at the ganglionic level (12). The function of GPR41 in sympathetic ganglia is consistent with the lower energy expenditure and obese phenotype of Gpr41 knockout mice reported by Bellahcene et al. (19). Furthermore, our laboratory showed that propionate increased the release of norepinephrine from sympathetic neurons through the GPR41-G $\beta \gamma$-phospholipase C (PLC) $\beta$ 3-ERK1/ 2synapsin 2 (synaptic vesicle-associated phosphoprotein) pathway $(12,20)$. In addition, we found that $\beta$-hydroxybutyrate $(\beta-\mathrm{HB})$ has a potent antagonistic effect on GPR41 (12). $\beta$-HB is a ketone body that can be produced in the liver under ketogenic conditions such as starvation, low-carbohydrate dietary intake, and diabetes. $\beta$-HB suppressed propionate-induced sympathetic activation in both primary cultured sympathetic neurons and mice $(12,20)$. However, acetoacetate, another major ketone body, had no significant effect (12).

Recently, another group demonstrated that SCFA-mediated GPR41 activation improves glucose tolerance by inducing intestinal gluconeogenesis via a gut-brain neural circuit (21). They found Gpr41 mRNA in the nerve fibers of the portal vein (21). The SCFA-fed rats exhibited improved glucose tolerance compared with standard-diet-fed rats. This effect of SCFA was abolished by portal denervation with capsaicin. Propionate infusion in the portal vein activated jejunum G6Pase, the rate-limiting enzyme for gluconeogenesis. On the other hand, $\beta-\mathrm{HB}$, an antagonist of GPR41, slightly decreased G6Pase activity when infused alone and reversed propionate-mediated induction of G6Pase (21). 
These findings suggest that GPR41 functions as an energy sensor in the peripheral nervous system to maintain energy homeostasis (Figure 1).

\section{CONCLUDING REMARKS}

It is clear that GPR41 plays a critical role in host energy regulation, although not all of the intracellular signaling cascades that are required for GPR41 function have been elucidated. We envisage that future studies of the interaction between gut microbiota and GPR41, with a particular focus on SCFAs, will provide a more complete picture of GPR41 biological function. Given the beneficial effects that SCFA-dependent GPR41 activation on regulation of metabolism, we suggest that modulating GPR41 by using synthetic ligands will be a promising therapeutic strategy for the treatment of metabolic disorders.

\section{REFERENCES}

1. Symonds ME, Sebert SP, Hyatt MA, Budge H. Nutritional programming of the metabolic syndrome. Nat Rev Endocrinol (2009) 5:604-10. doi:10.1038/nrendo. 2009.195

2. Cottrell EC, Ozanne SE. Developmental programming of energy balance and the metabolic syndrome. Proc Nutr Soc (2007) 66:198-206. doi:10.1017/ S0029665107005447

3. Bergman EN. Energy contributions of volatile fatty acids from the gastrointestinal tract in various species. Physiol Rev (1990) 70:567-90.

4. Flint HJ, Bayer EA, Rincon MT, Lamed R, White BA. Polysaccharide utilization by gut bacteria: potential for new insights from genomic analysis. Nat Rev Microbiol (2008) 6:121-31. doi:10.1038/nrmicrol817

5. Delzenne NM, Neyrinck AM, Backhed F, Cani PD. Targeting gut microbiota in obesity: effects of prebiotics and probiotics. Nat Rev Endocrinol (2011) 7:639-46. doi:10.1038/nrendo.2011.126

6. Henao-Mejia J, Elinav E, Jin C, Hao L, Mehal WZ, Strowig T, et al. Inflammasome-mediated dysbiosis regulates progression of NAFLD and obesity. Nature (2012) 482:179-85. doi:10.1038/nature10809

7. Brown AJ, Goldsworthy SM, Barnes AA, Eilert MM, Tcheang L, Daniels D, et al. The orphan G protein-coupled receptors GPR41 and GPR43 are activated by propionate and other short chain carboxylic acids. J Biol Chem (2003) 278:11312-9. doi:10.1074/jbc.M211609200

8. Le Poul E, Loison C, Struyf S, Springael JY, Lannoy V, Decobecq ME, et al. Functional characterization of human receptors for short chain fatty acids and their role in polymorphonuclear cell activation. J Biol Chem (2003) 278:25481-9. doi:10.1074/jbc.M301403200

9. Al-lahham SH, Roelofsen H, Priebe M, Weening D, Dijkstra M, Hoek A, et al. Regulation of adipokine production in human adipose tissue by propionic acid. Eur J Clin Invest (2010) 40:401-7. doi:10.1111/j.1365-2362.2010.02278.x

10. Xiong Y, Miyamoto N, Shibata K, Valasek MA, Motoike T, Kedzierski RM, et al. Short-chain fatty acids stimulate leptin production in adipocytes through the $\mathrm{G}$ protein-coupled receptor GPR41. Proc Natl Acad Sci U S A (2004) 101:1045-50. doi:10.1073/pnas.2637002100

11. Hong YH, Nishimura Y, Hishikawa D, Tsuzuki H, Miyahara H, Gotoh C, et al. Acetate and propionate short chain fatty acids stimulate adipogenesis via GPCR43. Endocrinology (2005) 146:5092-9. doi:10.1210/en.2005-0545
12. Kimura I, Inoue D, Maeda T, Hara T, Ichimura A, Miyauchi S, et al. Shortchain fatty acids and ketones directly regulate sympathetic nervous system via G protein-coupled receptor 41 (GPR41). Proc Natl Acad Sci U S A (2011) 108:8030-5. doi:10.1073/pnas.1016088108

13. Kimura I, Ozawa K, Inoue D, Imamura T, Kimura K, Maeda T, et al. The gut microbiota suppresses insulin-mediated fat accumulation via the shortchain fatty acid receptor GPR43. Nat Commun (2013) 4:1829. doi:10.1038/ ncomms 2852

14. Zaibi MS, Stocker CJ, O’Dowd J, Davies A, Bellahcene M, Cawthorne MA, et al. Roles of GPR41 and GPR43 in leptin secretory responses of murine adipocytes to short chain fatty acids. FEBS Lett (2010) 584:2381-6. doi:10.1016/j.febslet. 2010.04.027

15. Samuel BS, Shaito A, Motoike T, Rey FE, Backhed F, Manchester JK, et al. Effects of the gut microbiota on host adiposity are modulated by the short-chain fattyacid binding G protein-coupled receptor, Gpr41. Proc Natl Acad Sci US A (2008) 105:16767-72. doi:10.1073/pnas.0808567105

16. Tazoe H, Otomo Y, Karaki S, Kato I, Fukami Y, Terasaki M, et al. Expression of short-chain fatty acid receptor GPR41 in the human colon. Biomed Res (2009) 30:149-56. doi:10.2220/biomedres.30.149

17. Tolhurst G, Heffron H, Lam YS, Parker HE, Habib AM, Diakogiannaki E, et al. Short-chain fatty acids stimulate glucagon-like peptide-1 secretion via the Gprotein-coupled receptor FFAR2. Diabetes (2012) 61:364-71. doi:10.2337/db111019

18. Nøhr MK, Pedersen MH, Gille A, Egerod KL, Engelstoft MS, Husted AS, et al. GPR41/FFAR3 and GPR43/FFAR2 as cosensors for short-chain fatty acids in enteroendocrine cells vs FFAR3 in enteric neurons and FFAR2 in entericleukocytes. Endocrinology (2013) 154:3552-64. doi:10.1210/en.2013-1142

19. Bellahcene M, O’Dowd JF, Wargent ET, Zaibi MS, Hislop DC, Ngala RA, et al. Male mice that lack the G-protein-coupled receptor GPR41 have low energy expenditure and increased body fat content. Br J Nutr (2013) 109:1755-64. doi:10.1017/S0007114512003923

20. Inoue D, Kimura I, Wakabayashi M, Tsumoto H, Ozawa K, Hara T, et al. Short-chain fatty acid receptor GPR41-mediated activation of sympathetic neurons involves synapsin 2b phosphorylation. FEBS Lett (2012) 586:1547-54. doi:10.1016/j.febslet.2012.04.021

21. De Vadder F, Kovatcheva-Datchary P, Goncalves D, Vinera J, Zitoun C, Duchampt A, et al. Microbiota-generated metabolites promote metabolic benefits via gut-brain neural circuits. Cell (2014) 156:84-96. doi:10.1016/j.cell.2013. 12.016

Conflict of Interest Statement: The authors declare that the research was conducted in the absence of any commercial or financial relationships that could be construed as a potential conflict of interest.

Received: 02 April 2014; accepted: 13 May 2014; published online: 26 May 2014. Citation: Inoue D, Tsujimoto G and Kimura I (2014) Regulation of energy homeostasis by GPR41. Front. Endocrinol. 5:81. doi: 10.3389/fendo.2014.00081

This article was submitted to Diabetes, a section of the journal Frontiers in Endocrinology.

Copyright (c) 2014 Inoue, Tsujimoto and Kimura. This is an open-access article distributed under the terms of the Creative Commons Attribution License (CC BY). The use, distribution or reproduction in other forums is permitted, provided the original author(s) or licensor are credited and that the original publication in this journal is cited, in accordance with accepted academic practice. No use, distribution or reproduction is permitted which does not comply with these terms. 